\title{
SUPPORTING INNOVATION PROGRAMMES IN AFRICA: LEARNING FROM EXPERIENCE
}

\author{
Mansoor Ali*
}

\begin{abstract}
This paper is based on the author's experience of supporting innovation programmes in basic services across African countries between 2016 to date. The paper's background explains the need for innovation programming and emerging expectations from the governments and donors. The paper explains how this type of programming is different from traditional practices. In delivery, innovation programmes require an approach to take risks, do things differently, try out new approaches, learn continuously and regularly accept failures to improve the next action. The innovation in planning and practice expects to work with a range of stakeholders, often called 'eco-system' actors (Erik and Michiel, 2008). It expects to build on collective effort and collaboration to deliver the results. This includes governments support for innovation and for creation of space for this. The private sector is expected to invest in risk taking and users should reflect back on their experience of working with innovation. Innovation is also dependent on many small sized and invisible actors who could make things happen. Designing innovation programmes is different from traditional programming, as these programmes are expected to learn, adapt and change. Innovation programmes embrace complexity and non-linearity (Ramalingam and Jones, 2008) in their project cycles and have regular feedback loops within the project cycle. These programmes are assessed on the basis of new thinking, ideas and enhanced confidence of the innovator as compared to the situation at the start of the programme. Exit strategies and closure of innovation programming are also different, as compared to traditional programming. Innovation programmes are expected to show sustainability and adaptation by stakeholders, especially by the market and business. Increased knowledge, learning and interest of the business are some of the key indicators to be tested at the programme closing stage. Author's own experience suggests that, the key to success of innovation programming is about learning and the ability to integrate
\end{abstract}

innovation principles into the project selection, management and closures. Innovation programming is in early days and one of the main risks is that if innovation programming is managed as traditional programming it looses important principles. Based on author's overall experience, the paper makes recommendations on the preparation, selection and management of innovation programmes in low income industrializing countries.

Keyword: Innovative Programmes, Africa, Stakeholder, Community Traditional Programming.

\section{INTRODUCTION}

This paper is based on author's experience of advising on innovation programming in basic services, such as water, sanitation, hygiene improvement, health and solid waste management. Majority of these programmes, under discussion, were supported by the organisations based in the United Kingdom, including government, private sector and non-government organisations. The programmes were targeted for low income countries in the African region, where access to basic services is very low. The author was involved in planning, selection, supporting the management, technical support, reviews and evaluation of the projects. The premise of this paper is that innovation is a new way of doing things, and lessons can be learned for other developing countries.

\section{Drivers of Innovation Programming;}

There are many drivers for a need to do things differently i.e. programming innovatively. The main driver is the expectation that innovation programmes (IPs) have a greater chance to reach the poorest as compared to traditional programmes. There is an expectation that new approaches could be the game changer for hard to reach groups. The other driver is the critique and repeated failures of traditional

\footnotetext{
* Mansoor Ali, Visiting Professor, Loughborough University, UK Email Correspondance: mansoorali57@hotmail.com
} 
programming, especially as evident from some recent evaluations (ICAI, 2016). There is increasing concern that traditional programming only benefits the better off groups and the project outcomes do not sustain beyond the project lives i.e. sustainability is a common concern in many recent evaluations. For example, schools shut down after some time due to absence of teachers, hospitals lack staff and supplies and infrastructure does not fully operate due to shortage of skills and lack of necessary maintenance. There is a growing concern that traditional projects do not change the systems, norms and behaviors, as the prime motivation is often the implementation. Hence their contribution to building institutions, develop systems and offer learning can be marginal. These are some of the important drivers to consider new ways of doing things, hence innovation programming should be encouraged globally.

Global efforts to support new ways of doing things are supported in a number of ways by United Nations (UN) due to emerging goals. One important pathway is the UN support of Principles of Digital Development (PDD). Recognising that digitalization is a reality, these principles are supported in policies and practice relevant to development programing. PDD is a set of nine principles which supports digitalisation and its contribution to development. A summary of these principles is given below;

1) Design with the Users: To develop context-appropriate solutions informed by user needs. To include all user groups in planning, development, implementation and assessment. Develop projects in an incremental and iterative manner.

2) Understand the Ecosystem: To participate in networks and communities of like-minded practitioners. Align to existing technological, legal and regulatory policies.

3) Design for Scale: Design for scale from the start and assess and mitigate dependencies that might limit ability to scale. Employ a "systems" approach to design, considering implications of design beyond an immediate project.

4) Build for Sustainability: Plan for sustainability from the start, including planning for long-term financial health, e.g., assessing total cost of ownership.

5) Be Data Driven: Design projects so that impact can be measured at discrete milestones with a focus on outcomes (i.e. expected change) rather than outputs
6) Use Open Data: Source and Innovation; Adopt and expand existing open standards. Open data and functionalities, and expose them in documented APIs (Application Programming Interfaces) where use by a larger community is possible.

7) Reuse and Improve: Use, modify and extend existing tools, platforms and frameworks when possible.

8) Address Privacy and Security: Assess and mitigate risks to the security of users and their data.

9) Be Collaborative: Engage diverse expertise across disciplines and industries at all stages. Work across sector silos to create coordinated and more holistic approaches.

Most of the UN organisations integrating the PDD in their programmes to maximise the benefits of digitalization. Globally, there are also other drivers for innovation programming, including low carbon economy, employment creation and urbanization.

\section{Concerns over Traditional Programming}

In this paper the term 'traditional programming' has been used for those projects, programmes or other similar arrangements when an external organization supports activities to achieve a development outcome. These external organizations can be United Nations offices, a bilateral or multi-lateral donor or a private industry. These programmes are delivered with the permission or invitation of the governments in host countries. Historically, such programmes have been considered as a necessary component of the development process in meeting the needs for health, education, improved agriculture, communication etc. However, there are recurring concerns over traditional programming. These include, inability of traditional programmes to reach the poorest. Even those programmes which are designed to reach the poorest, end up serving the better off population. The other concern about traditional programming is the lack of certainty to sustain beyond the project period. Success is often reported within the project duration and once the project is over, challenges start to appear. Governments and communities are not able to support the project, as expected in the plans. Resources are not generated, or poorly used and trained staff tend to move elsewhere. One of the common weaknesses within the traditional programming is the lack of internal learning, biased documentation, lack of flexibility to change paths and lack of sharing with the sector. These concerns are 
Table 1: Expectation from Innovative Programming

\begin{tabular}{|l|l|}
\hline \multicolumn{1}{|c|}{ Issues in Traditional Programming } & \multicolumn{1}{c|}{ Expectation from Innovation Programing } \\
\hline Inability to reach the poorest & $\begin{array}{l}\text { Through connectivity poor people in remote regions can be } \\
\text { reached. }\end{array}$ \\
\hline Lack of internal learning and change & $\begin{array}{l}\text { Through an approach of working with the entire eco-system, } \\
\text { placed to continue work. }\end{array}$ \\
\hline Lack of internal learning and change & $\begin{array}{l}\text { Real time reflections, change and learning is supported } \\
\text { through behavior change. }\end{array}$ \\
\hline Lack of external learning & $\begin{array}{l}\text { Capturing learning and evidence can be better done and new } \\
\text { and more exciting methods of knowledge sharing can take } \\
\text { place. }\end{array}$ \\
\hline
\end{tabular}

repeatedly mentioned and come up in reviews and evaluations (ICAI, 2016). Traditional programming has also come under media pressure (Oxfam, 2018) in certain countries, leading to excessive checks and scrutiny. Table 1 shows the expectations from innovative programming which can help overcome the above concerns.

\section{Opportunities Offered by Innovation Programming}

Innovation builds on new opportunities, which were not present ten years ago in the form and scale available now. The innovation programming intends to build on those new opportunities available. These opportunities include:

Digitalization: Digital transfer of information and data make things easier and faster.

High Rates of Connectivity: Connectivity makes it easier to reach 'hard to reach' people, especially those where physical access is challenging.

Ease of Money Transfer: Payments and transfer of money is much faster, simpler and safer. Payments are made online and accountability and record keeping has enhanced as compared to manual handling of cash.

Real Time Feedback: Real time data and feedbacks help users with a choice. It informs the systems of the demand for the service at a particular time e.g. waste vehicles operating on fixed routes versus waste trucks follow the signals from the sensors.

Access to Recent Maps and Use of Maps: Many countries have a better access to maps and GIS locations. These maps come with applications (APPs) and are easy to access.
Introduction of Gaming and Fun: Rather un-intentionally, gamming is introduced into the system when information is available in a more fun and easier to access format.

These are some of the opportunities available to use for innovation. Innovation programming expect to use these opportunities to improve services, reduce cost and enhance reach. For example, teaching is made possible in remote villages of Africa (Internet Society, 2017) without schools and resident teachers due to better connectivity through internet and mobile phones. Similarly, payments are possible without physical bank branches or cash machines and certain type of health consultations are possible without physical presence of doctors and nurses.

While there are important opportunities available to enhance innovation, there is very little consensus available on how innovation should be nurtured and supported. There is very little understanding on the types of innovation and on how education and training should be provided for innovation. There is a school of thought suggesting that innovation and creativity must not be taught in the class room, as the class room space expected norms and structured approaches may counter the creativity and innovation. The discussions on innovation is often restricted to the discussion on new technologies. Nevertheless, some organisations have attempted to explain innovation and its typology. One of those is known as Doblin's Principles (Doblin, 2015).

These groups are mostly based on Doblin's group experience with the industry and commercial sector. But the application of the principles is not restricted to these groups. In summary Doblin (2015) classifies innovation into ten categories (adapted by the author for this paper): 
Profit Models: The way in which one makes money, charges are assigned and fees are collected with a motive to increase revenue and profits.

Network: Connections and collaboration with others are established to create value.

Structure: Alignment of the talent and asset in an organizational context.

Process: Improved methods for doing work.

Product Performance: Distinguishing features and functionality of a product.

Product System: Complementary products and services.

Service: Regular support and enhancements that comes with your offerings.

Channels: Delivery of offerings to customers and user.

Brand: Representation of offerings and businesses.

Customer Engagement: Distinctive interactions that are fostered.

The above typology and their combination are what Doblin (2015) suggests for innovation.

With the above discussion in mind, the paper presents some examples of the innovation programming.

\section{Examples of Innovation Programming}

Below are some examples of the Innovation Programming, where the author has been involved.

\section{Human Development Innovation Fund (HDIF)}

HDIF calls itself a learning platform for innovation in Tanzania. This is a five years programme supported by the UK government. HDIF aims to support better understanding and knowledge around innovation in human development, and to use evidence from HDIF to support the transformation of the innovation space, through adoption and scale up of innovations in Tanzania. This programme closely works with the national government and uses commercial sector, youth led enterprises and research institutions to achieve common goals. The project works in many sectors, including health, education, water and sanitation.

\section{UKAID -Uniliver TRANSFORM Programme}

TRANSFORM is an exploratory programme that started in partnership between UK Government and Uniliver PLC in 2015. It aims to use and bring creativity used in private sector and commercial approaches to solve persistent global development challenges, such as water, sanitation and hygiene improvement. To date, it has supported nineteen projects across nine countries, which have already benefited over a quarter of a million people. The portfolio includes a mobile platform for shopkeepers in Kenya that encourages them to become change agents in their communities, and a portable handwashing station for low-income households in Bangladesh. This next phase will quadruple the size of the programme, from $£ 10$ million to $£ 40$ million, to support market-based solutions that meet low-income household needs in developing countries. Through financial and business support for social enterprises and behaviour-change interventions, TRANSFORM's aim is to enable one hundred million people in sub-Saharan Africa and Asia to gain access to products and services that have been shown to improve health, livelihoods, the environment or wellbeing by 2025 .

\section{Humanitarian Innovation Fund (HIF)}

The Humanitarian Innovation Fund (HIF) supports organisations and individuals to identify, nurture and share innovative and scalable solutions to the challenges facing humanitarian sector (i.e. emergencies, relief and disasters). HIF was launched in 2010 and considers itself a leading actor in supporting the development and testing of approaches to innovation in the humanitarian system. HIF is an independent grant-making organisation focused on humanitarian innovation - uniquely open to the full diversity of actors working in the humanitarian system. HIF offers grants, help organisations to take ideas to scale, generate and disseminate knowledge.

It is worth highlighting here that the above three programmes use a different set of concepts in their funding calls, programme management and exit strategies, as compared to traditional programmes. Some of these also encourage applicants to think in terms of innovation programme typology, such as the stage of innovation, type of innovation and level of confidence they have. These programmes encourage applicants to develop business plans and not just a funding proposal, focused on the project delivery. The programme expects the applicants to understand and highlight the risks and predict failures. Most importantly, there is emphasis on learning and using the potential of entire ecosystem to encourage sustainability of the project. 


\section{Lessons and Learning from Innovation Programming}

Based on author's involvement in innovation programming certain lessons can be drawn.

1) Innovation programming opens up new opportunities to deliver development outcomes. This potential is currently being used and success has started to emerge. This is a stage, when more learning is to be explored about the reasons and the extent of the success. However, success and failure may be less important since innovation programming is to nurture new ways of working. It is more important to understand and report those areas within programming where innovation is making a difference, rather than declaring innovation as the panacea. This work is to be done and would benefit future programmes.

2) Innovation programming communicates very well across all the programmes reviewed for this paper. In the above three examples, there are user friendly systems in place, social media is fully used and the websites are user friendly. There are many places for knowledge sharing in different forms to suit different readers, human friendliness in presentations and many documents to learn about the processes, often in simple to understand format. In addition, all the programmes have fully used mobile phones and internet to communicate with the programme beneficiaries. This improves the flow of information, engagement and contributes to accountability.

3) Many programmes have used improved ways of engagement between different players. especially the use of eco-system analysis and promotion of Human Centered Design (or Users Centered Design) approaches in designing the interventions. This approach is originally started by commercial businesses to develop products and services. The application is used innovatively to empower the users and to design the interventions with them.

4) Furthermore, the current era of innovation programming is very exciting. Many new discoveries are taking place. Innovation programming is done to learn, share and scale- up interventions. Many programmes are based on knowledge and promoting learning. However, more research is needed to identify targets for knowledge and learning that is emerging from this type of programming, the users of learning and how and why these groups require learning, and what is expected from these groups?

5) Handing over and exit of innovative programming is another important area for research. Traditional programmes expect to handover to the government or community groups, and this may continue on the similar principles. For innovation programing the main purpose is to develop viable business models based on learning. The viable business models are expected to be taken up by businesses and necessary changes may be needed in policy support. This may mean a partnership of innovation programing, research institutions and governments. The handing over and exit phases are the most important parts of the programming, keeping in mind the main purpose of innovation programming.

6) More research is needed on the typology of contract management, risk taking and safeguards for innovation programming. Innovation programmes are expected to accept and embrace complexity. This needs to translate into the actual contract management, training and behaviours of the managers. Embracing complexity means change of plans, accepting failures, change of pathways and testing of ideas becomes a day to day practice. Traditional contract management, including the components of financial and human resources management are not designed as per complexity principles. A cross organizational campaign is needed to build awareness about complexity and its use in the innovation programming.

7) One of the potential risk of innovation programming is the control over technologies for large profit making organisations. While PDD expects more open source approaches and ownership of the local organisations, innovation programming can be a pathway for more profit making. This risk needs careful handling through short and long term contracts. 


\section{REFERENCES:}

Doblin, 2015, "Doblin Ten Types of Innovation - The Building Blocks of Breakthrough", viewed 03-03-2018, from https://www.doblin.com/ten-types/\#framework.

Erik, Den H. and Michiel, T., 2008, Encyclopedia of Network and Virtual Organizations, IGI Global Knowledge and Delft University of Technology, The Netherlands.

ICAI, 2016, “An Impact Review of DFID WASH Portfolio”, Independent Commission of Aid Impact (ICAI), UK viewed 06-09-2018, from https://icai.indepent.gov.uk/html-report/wash.

Internet Society, 2017, "Internet for Education in Africa", Helping Policy Makers to Meet the Global Education Agenda Sustainable Development Goal 4, Internet Society Publication.

Oxfam, 2018, “Oxfam Allegations in the Media”, viewed 06-08-20018, from https://www.bbc.co,uk/news/uk-43112200

Ramalingam, B. and Jones, H. 2008 "Exploring the Science of Complexity: Ideas and Implications for Development and Humanitarian Efforts", ODI Working Paper 285, Overseas Development Institute, London. 